\title{
LA PROTECCIÓN DE ADULTOS EN EL DERECHO INTERNACIONAL PRIVADO ESPAÑOL: NOVEDADES Y RETOS
}

\author{
Salomé AdROHER BIOSCA*
}

SUMARIO: 1. INTRODUCCIÓN.-2. COMPETENCIA JUDICIAL INTERNACIONAL.-3. DERECHO APLICABLE.-3.1. Medidas ex ante.-3.2. Medidas ex post.-4. RECONOCIMIENTO Y EFICACIA DE DECISIONES JUDICIALES EXTRANJERAS Y DE DOCUMENTOS PÚBLICOS EXTRANJEROS.-5. COOPERACIÓN INTERNACIONAL DE AUTORIDADES.-6. CONSIDERACIONES FINALES.

\section{INTRODUCCIÓN}

1. El aumento de las modificaciones de capacidad, tutelas y en general, medidas de protección de adultos vinculadas a diversos países, unidos a los diferentes modelos de protección en Derecho comparado, justifican la actualidad de las cuestiones de Derecho internacional privado en la materia ${ }^{1}$. Diversas resoluciones judiciales y administrativas recientes son una buena muestra de ello ${ }^{2}$. Los tradicionales presupuestos sociológico y jurídico que

* Profesora propia ordinaria de Derecho internacional privado. Universidad Pontificia Comillas. (s.adroher@comillas.edu). Todas las páginas web de referencia han sido consultadas por última vez el 16 de noviembre de 2018. Trabajo realizado en el marco del proyecto de investigación del Plan nacional $\mathrm{I}+\mathrm{D}+\mathrm{I}$ : Prospectiva sobre el ejercicio de la capacidad: la interrelación entre las reformas legales en materia de discapacidad y menores. DER2016-75342-R (IP: María Victoria Mayor). 2016-8.

1 Un tratamiento general en Frimston, R., Ruck KeEne, A., van OverdiJK, C. y Adrian Ward, A., International Protection of Adults, Oxford University Press, 2015.

2 Es el caso de la Sentencia del Tribunal de Justicia de la Unión Europea (TJUE), Sala 2. ${ }^{\text {, de }} 16$ de noviembre de 2016, caso Wolfgang Schmidt c. Christiane Schmidt (ECL:EU:C: 2016:881), que aborda una demanda de anulación de una donación de un bien inmueble situado en Austria hecha por un padre a su hija (residentes en Austria y Alemania, respectivamente). El padre fue sometido a tutela tras la donación y en la resolución judicial se apreciaba que padecía trastornos psiquiátricos con anterioridad a la donación. Es también el caso resuelto por la STS núm. 145/2018 (Sala de lo Civil, Sección 1. a), de 15 de marzo (RJ 2018/1478) en la que unas hijas solicitan la nulidad del segundo matrimonio de su padre contraído en China con una súbdita de este país y a la cual nombra heredera en su testamento, alegando la modificación de la capacidad del padre por el Alzheimer que padecía dictada por un juz- 
determinan la existencia del Derecho internacional privado son evidentes en este sector, como expondré brevemente a continuación.

2. El impacto sociológico de este tema en nuestro país es indudable. Si bien no existen estadísticas oficiales en España sobre el número de personas cuya capacidad ha sido modificada judicialmente, «se barajan datos de entre 250.000 y 400.000 personas sometidas a sentencias de incapacitación judicial» ${ }^{3}$, y entre ellos, cada vez es más destacable la presencia de extranjeros.

En efecto; en los últimos años ha crecido considerablemente el número de extranjeros que han llegado a España con motivo de su jubilación, al elegir nuestro país para pasar sus últimos años de vida, fenómeno al que se ha denominado la "gerontoinmigración» ${ }^{4}$. La incidencia en esta población de patologías y enfermedades asociadas a la edad, particularmente el Alzheimer, está originando que nuestros juzgados, servicios sociales, notarías y registros civiles se enfrenten, cada vez con más frecuencia, a problemas del Derecho internacional privado relativos a la protección internacional de adultos.

El número de extranjeros mayores que viven en España difiere según se tomen en cuenta los datos basados en los permisos de residencia o certificados de registro publicados en el portal de inmigración ${ }^{5}$, o los datos del padrón de habitantes publicados por el Instituto Nacional de Estadística (INE) ${ }^{6}$. Sin embargo, ambas fuentes confirman el evidente el aumento del número de extranjeros mayores residentes en España.

En menos de diez años, los mayores de sesenta y cinco años extranjeros residentes en España son más del doble:

\begin{tabular}{|l|c|c|c|c|c|c|c|c|c|}
\hline & $\mathbf{2 0 0 9}$ & $\mathbf{2 0 1 0}$ & $\mathbf{2 0 1 1}$ & $\mathbf{2 0 1 2}$ & $\mathbf{2 0 1 3}$ & $\mathbf{2 0 1 4}$ & $\mathbf{2 0 1 5}$ & $\mathbf{2 0 1 6}$ & $\mathbf{2 0 1 7}$ \\
\hline Total & 2.204 .687 & 2.376 .108 & 2.526 .829 & 2.622 .052 & 2.691 .177 & 2.773 .707 & 2.873 .554 & 2.977 .850 & 3.124 .590 \\
\hline Mayores de 65 & 153.372 & 164.722 & 181.500 & 206.035 & 227.024 & 249.616 & 270.618 & 292.904 & 320.292 \\
\hline
\end{tabular}

A 1 de enero de 2018, 4.719.418 extranjeros estaban empadronados en España. De ellos, 317.869 eran mayores de sesenta y cinco años, de los cuales 244.615 eran europeos.

gado español cinco meses después de la celebración del matrimonio; o, finalmente, es el caso resuelto por la Resolución de la Dirección General de Registros y del Notariado (DGRN) núm. 4712/2018, de 23 de marzo (RJ 2018/1886), en la que el tutor de un súbdito alemán vende en su nombre una vivienda que este tiene en España.

${ }^{3}$ Proposición no de Ley del Grupo socialista relativa a la confección de una estadística pública sobre procedimientos judiciales de incapacitación o de modificación de la capacidad de obrar (BOCG, CD. XII legislatura, 28 de febrero de 2017).

${ }^{4}$ Término acuñado por el grupo de investigación de la profesora Echezarreta Ferrer que administra una web con importante información: http://www.gerontomigracion.uma.es/.

${ }^{5}$ Los datos totales son de extranjeros con certificado de registro o de familiar o de tarjeta de residencia en vigor. Los cuadros son elaboración propia a partir de las estadísticas publicadas en el portal de inmigración (http://extranjeros.empleo.gob.es/).

${ }^{6}$ https://www.ine.es. 
Las nacionalidades más relevantes de esta población mayor extranjera que residen en España son europeas. En el siguiente cuadro se recogen las diez más numerosas en 2017 y en negrita se señalan, de entre esos países, cuales son los que han ratificado el Convenio de La Haya sobre protección internacional de adultos (HAPC en las siglas inglesas que voy a emplear) de 13 de enero de 2000, al que haré alusión en este trabajo.

\begin{tabular}{|l|c|c|c|c|c|c|c|c|c|}
\hline R. Unido & Alemania & Italia & Francia & Rumania & $\begin{array}{c}\text { Países } \\
\text { Bajos }\end{array}$ & Portugal & Bélgica & Bulgaria & Noruega \\
\hline 112.686 & 36.574 & 21.731 & 20.821 & 18.795 & 13.192 & 10.261 & 9.959 & 7.693 & 6.523 \\
\hline
\end{tabular}

Tal como puede apreciarse, la población mayor británica es la más numerosa en nuestro país. Según el INE, a 1 de enero de 2018, el número de británicos residentes en España mayores de sesenta y cinco años era de 88.507, si bien «extraoficialmente» se calcula que hay más de medio millón de británicos residentes en España cuya media de edad es de cincuenta y siete años y medio; los efectos del Brexit en esta población ya están comenzando a apreciarse ${ }^{7}$.

La gerontoinmigración presenta una concentración territorial en ciertas provincias o CCAA. Según los datos de extranjería, en 2017 las más relevantes fueron Alicante (76.904), Canarias (41.554), Málaga (41.077), Madrid (23.293) y Baleares (18.765). Esto supone que los operadores jurídicos de estos territorios se enfrentan con más frecuencia a los problemas derivados de la modificación de la capacidad y protección de ciudadanos extranjeros.

Por otra parte, también ha aumentado en España la presencia de inmigrantes económicos, refugiados y desplazados, incluidos en los datos de extranjeros residentes, y esta población, aunque joven, puede verse afectada también por alguna medida necesaria de protección. Así, por una parte, la psicología ha identificado que, en algunos casos, los desplazados internacionales presentan problemas de salud mental asociados al estrés post-traumático que han vivido, tanto si son adultos como menores ${ }^{8}$; por otra, en los

\footnotetext{
${ }^{7}$ Ha habido estudios relevantes sobre los efectos del Brexit en relación a esta población británica que ponen de relieve no solo los problemas derivados del nuevo estatuto de extranjería, sino también del cobro de pensiones, atención sanitaria, etc. En particular, los de Echezarreta Ferrer, M. T., «Incidencia del Brexit en la movilidad transfronteriza de jubilados británicos: algunas coincidencias con las relaciones hispano-gibraltareñas», en Martín Martínez, M. M. y Martín y Pérez de Nanclares, J., (coords.), El Brexit y Gibraltar: un reto con oportunidades conjuntas, Madrid, Ministerio de Asuntos Exteriores y Cooperación, 2017, pp. 239-260; DURÁN MUÑOZ, R., «España como lugar de retiro en tiempos del Brexit», REDI, vol. 70, 2018, núm. 2, pp. 231-238.

8 Achotegui, J., «Emigrar en situación extrema: el Síndrome del inmigrante con estrés crónico y múltiple (Síndrome de Ulises)», Norte de salud mental, 2004, núm. 21, pp. 39-52; Jurado, D., Alarcón, R., Martínez-Ortega, J. M., Mendieta-Marichal, Y., Gutiérrez-Rojas, L. y Gurpegui, M., «Factors associated with psychological distress or common mental disorders in migrant populations across the world», Revista de Psiquiatría y Salud Mental (English Edition), vol. 10, 2017, núm. 1, pp. 45-58; SALABerria ItZiar, K. y del Valle SÁnchez de Haro, A., «Estrés migratorio y salud mental», Psicología Conductual, vol. 25, 2017, núm. 2, pp. 419-432; Crespo, M., Steffany Castro, C. y Gómez Gutiérrez, M.,
} 
casos de reagrupación familiar, los reagrupantes suelen priorizar a sus familiares con algún tipo de discapacidad ya que en nuestro país existen mayores recursos y nivel de atención a estas personas que en sus países de origen. Finalmente, también se han dado casos de inmigrantes que han sufrido un accidente de circulación o laboral a resultas del cual han quedado afectados de una severa discapacidad. Es por ello que también a este sector de población le puede afectar una medida judicial de modificación de la capacidad y nombramiento de tutor u otra figura de protección.

3. Junto a esta realidad sociológica cada vez más «internacionalizada», los modelos de protección de la persona adulta no son homogéneos en Derecho comparado, tanto en lo relativo a la existencia de procedimientos de modificación de la capacidad y a la naturaleza contenciosa o voluntaria de los mismos, como en lo relativo a la inscripción registral de las decisiones judiciales que afectan a la capacidad.

Tal y como se señalaba en uno de los estudios más completos publicados en España en la materia al que sigo en este punto, existen tres modelos básicos en Derecho comparado y, por tanto, una diversidad jurídica que reclama una respuesta del Derecho internacional privado en la materia ${ }^{9}$.

En el modelo tradicional, al que cabe adscribir el actual Derecho español ${ }^{10}$, algunos sistemas jurídicos europeos y gran parte de los iberoamericanos ${ }^{11}$, la protección de las personas «incapaces» supone la restricción total o parcial de su capacidad de obrar, normalmente acompañada del nombramiento judicial de un tutor representante legal o en su caso de un curador, nombramiento que deberá determinar los actos para los que resulte preceptiva su intervención o autorización.

Un segundo grupo de sistemas jurídicos, encuadrados bajo el denominado modelo tradicional funcionalmente modificado, se caracterizan por contemplar una variedad de medidas protectoras que permiten una respuesta más flexible en función de la necesidad del adulto, respondiendo a los principios de proporcionalidad y necesidad. Se concede especial trascendencia a la protección y a la asistencia equiparando la protección personal a la patrimonial ${ }^{12}$.

\footnotetext{
«Menores refugiados. Psicopatología y factores relacionados», Revista de Victimología, 2017, núm. 6, pp. 9-32.

9 Caro Gandara, R., «La protección de los adultos discapaces en Derecho comparado. Sistemas más representativos», en EchEZARRETA FERRER, M., El lugar europeo de retiro. Indicadores de excelencia para administrar la gerontoinmigración de ciudadanos de la Unión Europea en municipios españoles, Granada, Comares, 2005, pp. 303 y ss.

10 Un estudio, entre otros, sobre el sistema español es el de GonzÁlez Poveda, P. y Picón Martín, M. (dirs.), Los discapacitados y su protección jurídica, Madrid, Estudios de Derecho Judicial, 2000.

${ }_{11}$ En la página web de la CIEC se recogen las líneas generales de algunos sistemas jurídicos que básicamente responden a este modelo: Grecia, Luxemburgo, Polonia y Hungría, entre otros, http:// www.ciec1.org.

12 Es el modelo adoptado en Francia tras la Ley de 5 de marzo de 2007 que introduce novedades como el «mandato de protección futura», los «mandatarios judiciales de protección de mayores», la «medida de acompañamiento social personalizado» y la «medida de acompañamiento judicial». Es también el modelo suizo. En este país la función tutelar corresponde al Estado a través de las autori-
} 
Finalmente, el modelo progresivo es en el que se enmarcan los sistemas jurídicos británico y alemán, las dos nacionalidades de gerontoinmigrantes más numerosas en España ${ }^{13}$. Se simplifican los instrumentos de protección que se reducen a un único mecanismo suficientemente flexible para adaptarlo a las necesidades de cada caso, mecanismo que puede ser de competencia administrativa o judicial y cuya adopción no requiere necesariamente la previa declaración de incapacitación ${ }^{14}$.

Al margen de estos tres modelos civiles, existen también diferencias en el tratamiento registral. En determinados países la adopción de medidas de protección no tiene publicidad registral; en otros, la publicidad se lleva a cabo según la medida de protección adoptada en diversos registros y a través de distintos sistemas; y en fin, en otros, la publicidad consta básicamente en el Registro civil ${ }^{15}$.

4. El tradicional marco legal español en materia de modificación de capacidad está sometido a un proceso de reforma necesario debido a la incorporación a nuestro ordenamiento jurídico de las previsiones de la Convención de Naciones Unidas sobre los Derechos de las Personas con Discapacidad hecha en Nueva York el 13 de diciembre de 2006 (CNUDPD) y ratificada en 2008 por España ${ }^{16}$. La reforma del Derecho español ${ }^{17}$, en línea con las de otros sistemas jurídicos de nuestro entorno, recogerá principios tales como la diversificación y flexibilización de las medidas de protección adaptándolas en función de la proporcionalidad y la subsidiariedad a la situación real del protegido, la creciente importancia de la autonomía de voluntad del sujeto y la progresiva administrativización en el modelo de protección ${ }^{18}$. La perspec-

dades de tutela, si bien los cantones pueden instituir, además, otras autoridades de carácter consultivo y ciertos órganos auxiliares.

${ }_{13}$ CARo Gándara, R., «La protección de las personas mayores incapaces en Alemania y Reino Unido", en PÉREz García, J. M. (coord.), La protección de las personas mayores apoyo familiar y prestaciones sociales: ponencias y comunicaciones del Congreso Internacional «La Protección de las personas mayores», Córdoba, 2009.

14 En Inglaterra y Gales, la Mental Capacity Act de 2005 en vigor desde 2007, se basa en los principios del respeto a la autonomía de la voluntad (a través en este caso de un apoderamiento preventivo -lasting power of attorney - $\mathrm{y}$ las voluntades anticipadas —advanced decisions-), $\mathrm{y}$ crea la figura de un «representante jurídico» profesional para los casos en los que no exista familiar o amigo que pueda cumplir esta función y una nueva jurisdicción especializada en la materia. En Alemania, por Ley de 1 de enero de 1992 se modificaron los arts. 896 a 908 del EGBGB que suprimieron la incapacitación, sustituyéndola por el Betreuungsgsgesetz: los tribunales del domicilio del sujeto con una discapacidad pueden nombrar un Betreuer cuando no exista otra forma de cuidar o asistir al protegido para que realice aquellos negocios jurídicos que el protegido no puede realizar por sí mismo, sin que eso signifique que este pierda capacidad de obrar. Sin embargo, el Tribunal puede limitar la capacidad del asistido en algunos casos, estableciendo el consentimiento previo del asistente en caso necesario.

15 En la página web de la Comisión Internacional de Estado Civil (CIEC) se ponen de relieve algunas de ellas, en relación a los países miembros de esta organización, http://www.ciec1.org/GuidePratique/index.htm.

${ }_{16}$ BOE núm. 96, de 21 de abril de 2008.

17 Anteproyecto de Ley por el que se reforma la legislación civil y procesal en materia de discapacidad aprobado en primera vuelta por Consejo de Ministros el 21 de septiembre de 2018.

18 MuÑoz Fernández, A., «Intervención pública y autonomía de la voluntad en la protección internacional de los incapaces», Persona y Derecho, 2015, núm. 72, pp. 287-300. 
tiva de los derechos fundamentales de los mayores vulnerables es, además, imprescindible ${ }^{19}$, y en ella debe advertirse la distinción entre las medidas ex ante, cada vez más frecuentes y que refuerzan precisamente la autonomía del sujeto para decidir su modelo de protección antes de que se produzca el menoscabo en sus capacidades, y las medidas ex post adoptadas por autoridades administrativas o judiciales una vez que el problema de salud se ha presentado $^{20}$.

5. También las normas de Derecho internacional privado español debían modificarse por diversos problemas prácticos que generaba su aplicación ${ }^{21}$. Algunas de estas carencias han sido objeto de reformas legales en $2015^{22}$.

En primer lugar, las normas que determinan la competencia judicial internacional de nuestros tribunales fueron modificadas por Ley Orgánica 7/2015, de 21 de julio, por la que se modificó la Ley Orgánica 6/1985, de 1 de julio, del Poder Judicial (LOPJ) ${ }^{23}$.

En segundo lugar, el art. 9.6 del Código Civil (CC) que regula el Derecho aplicable a estas medidas de protección fue modificado por Ley 26/2015 de modificación del sistema de protección a la infancia y a la adolescencia ${ }^{24}$.

En tercer lugar, el sistema de reconocimiento extraterritorial de estas medidas de protección ha sido regulado ex novo por la Ley 15/2015, de 2 de julio, de la Jurisdicción Voluntaria (LJV) ${ }^{25}$, y en relación a los efectos registrales en la Ley de Registro civil (LRC) ${ }^{26}$.

Finalmente, la Ley 29/2015, de Cooperación Judicial Internacional en Materia Civil (LCJIMC) contiene, por vez primera, normas de cooperación internacional de autoridades españolas con sus homólogas de otros países ${ }^{27}$.

6. En este trabajo analizaré este nuevo marco jurídico y su aplicación jurisprudencial ${ }^{28}$. No obstante, a pesar de estas modificaciones, ciertamente

19 Martínez Ques, A., «La protección jurídica de las personas mayores desde la perspectiva de los derechos humanos», Revista de Derecho UNED, 2015, núm. 17, pp. 1067-1102.

20 Curry-Sumner, I., "Vulnerable Adults in Europe. European added value of an EU legal instrument on the protection of vulnerable adults", en SALM, C. (author), y BERGERON, J. (Rapporteur), Protection of Vulnerable Adults. European Added Value Assessment Accompanying the European Parliament's Legislative Initiative Report, European Parliament, 2016, p. 52.

${ }^{21}$ Analizados entre otros en Adroher BioscA, S., "La protección de los mayores vulnerables: una cuestión pendiente», en Llamas Pombo, E. (coord.), Nuevos conflictos del Derecho de familia, Madrid, La Ley, 2009, pp. 719-757.

22 Vaquero LóPez, C., «Nuevas normas de Derecho internacional privado estatal en materia de protección de adultos y de menores», AEDIPr, vol. XVI, 2016, pp. 397 y ss.

${ }^{23} B O E$ núm. 174, de 22 de julio de 2015.

24 BOE núm. 180, de 29 de julio de 2015 .

25 BOE núm. 158, de 3 de julio de 2015.

26 Ley 20/2011, de 21 de julio, del Registro Civil (BOE núm. 175, de 22 de julio de 2011) cuya entrada en vigor se ha retrasado al 30 de junio de 2020 .

27 BOE núm. 182, de 31 de julio de 2015.

28 Agradezco a los magistrados Dolors Viñas Farré de la AP de Barcelona, M. ${ }^{a}$ Dolores Ruiz Ramos del Juzgado núm. 95 de Madrid y José Miguel Bort Ruiz de la AP de Guadalajara, las resoluciones judiciales inéditas que me han facilitado y que se citan a lo largo del estudio. En varios casos se transcribe su contenido, bien por su importancia, o bien por su carácter inédito. 
positivas, es altamente conveniente que España firme y ratifique el HAPC. Su incorporación al Derecho español supondría un marco legal homogéneo y erga omnes tanto respecto de las normas de competencia judicial internacional (con excepciones) como respecto de las de Derecho aplicable. Por otra parte, facilitaría el reconocimiento extraterritorial de decisiones así como la cooperación de autoridades respecto de los otros Estados parte, que son precisamente los países de origen de la gerontoinmigración presente en España $^{29}$.

La conveniencia jurídica y política de que esa firma y ratificación coincidiera con la reforma del Derecho sustantivo español en la materia es evidente. Este Convenio regula de forma completa las cuatro grandes cuestiones a las que acabo de aludir y determina su objeto con gran amplitud abarcando no solamente las instituciones tradicionales sino también las de "asistencia»; su aplicación, además, no depende de una incapacitación previa ${ }^{30}$.

Junto a este Convenio y en estrecha conexión con este tema, se ha señalado la necesidad de ratificación por España del Convenio de La Haya sobre ley aplicable al trust y a su reconocimiento de $1985^{31}$, texto plenamente compatible y complementario al anterior, toda vez que una de las modalidades de los denominados familiar trust, son trust for the disabled de aplicación particular en estos $\operatorname{casos}^{32}$.

7. A pesar de la indudable influencia de estas situaciones en el ámbito de la Unión Europea (UE) en la medida en que afectan al derecho a la libre circulación de muchos ciudadanos europeos y al adecuado funcionamiento del mercado interior, llama la atención que no haya instrumentos jurídicos que directamente regulen esta cuestión, aunque algunos reglamentos UE afecten a materias conexas ${ }^{33}$. En diversos trabajos se ha reclamado a la UE que se

${ }_{29}$ Han ratificado el Convenio los siguientes países: Alemania, Austria, Chipre, Estonia, Finlandia, Francia, Letonia, Mónaco, Portugal, Reino Unido, República Checa y Suiza.

30 Algunos recientes estudios sobre el Convenio son los siguientes: ANDERson, J. y RuCK KeEnE, A., "The 2000 Hague Convention on the International Protection of Adults: five years on», International Family Law, vol. 2, 2014, pp. 91-95; entre nosotros, Álvarez ToRnÉ, M., «Current Issues in the protection of adults from the perspective of private international law», Revista Electrónica de Estudios Internacionales, 2016, núm. 32.

31 IRIARTE ÁNGEL, J. L., «La protección de adultos en derecho internacional privado», en BorRÁs Rodríguez, A. (ed. lit.), Garriga Suau, G. (ed. lit.), Adaptación de la legislación interna a la normativa de la Unión Europea en materia de cooperación civil: homenaje al prof. Dr. Ramón Viñas Farré, Madrid, Marcial Pons, 2012, pp. 203-218.

32 Un reciente y documentado estudio sobre este tipo de trust en el que se pone de manifiesto, entre otras cuestiones, su aplicación en Italia a raíz de la ratificación por este país de tradición jurídica cercana a la española del Convenio de La Haya de 1985, es el de MARTín SANTIESTEBAN, S., «El patrimonio de destino de la Ley de protección patrimonial de las personas con discapacidad: Un acercamiento al trust?», Actualidad Jurídica Aranzadi, 2004, núm. 612, pp. 1-6. La ratificación de este Convenio por España permitiría, además, dar respuesta adecuada a otros tipos de trust cuyos efectos o validez están llegando ya a los tribunales españoles, como es el caso del reciente ATS (Sala de lo Civil, Sección 1. . $^{\text {) }}$ de 28 de febrero de 2018 (RJ 2018/1040).

33 Curry-Sumner, I., op. cit., nota 20, recuerda diversos Reglamentos que pueden incidir en aspectos relacionados con la actuación de una persona sujeta a protección. De todos ellos, el de sucesiones es el que presenta mayor conexión por la materia. A este respecto puede verse el reciente y documen- 
sirva de su competencia externa para requerir a los Estados miembros que se conviertan en Estados parte del HAPC «en interés de la UE», y en el Parlamento Europeo se ha presentado el 3 de abril de 2017 el Informe sobre la protección de los adultos vulnerables ya citado en el que se solicitó a la Comisión que presentase al Parlamento Europeo y al Consejo, antes del 31 de marzo de 2018, una propuesta de Reglamento en la materia:

«Based on Article 81 TFEU (81(1), 81(2)(a), (c), (d) (e), (f)), the EU could adopt legislatives measures to address the problems faced by vulnerable adults in cross-border situations and supplement the framework provided by the Hague Adult Protection Convention, which does not allow all cases of protection to be dealt with in the best interest of the adult concerned ${ }^{34}$.

8. En los siguientes epígrafes analizaré la respuesta de nuestro sistema estatal vigente tanto en los casos en los cuales la medida de protección es adoptada en España en las que debe determinarse la competencia judicial internacional de nuestras autoridades (2) y el Derecho aplicable por las mismas (3) como los casos en los que la medida se ha adoptado en el extranjero y se pretende su reconocimiento en España (4). Finalmente abordo algunas cuestiones relativas a la cooperación internacional de autoridades (5). Como podrá advertirse, el trabajo abunda en los aspectos de Derecho aplicable, lo cual se justifica en que este ha sido el ámbito que más cuestiones ha suscitado en la práctica, como confirma la jurisprudencia y doctrina registral analizada y como me han puesto de relieve los magistrados que he consultado en este trabajo y en el anterior ${ }^{35}$.

Al hilo de la exposición de la regulación española, iré analizando las soluciones aportadas por el HAPC de deseable ratificación tanto por nuestro país como por otros de la Unión Europea, tal y como ha reclamado hace ya diez años el Parlamento Europeo que apunta, entre otros países «pendientes»a España ${ }^{36}$.

\section{COMPETENCIA JUDICIAL INTERNACIONAL}

9. Antes de analizar los criterios competenciales de nuestras autoridades judiciales para la adopción de una medida judicial de modificación de la capacidad, de constitución de una tutela, o en general de protección, conviene

\footnotetext{
tado trabajo sobre el mismo en el que se analiza su aplicación en España de ReQuEJo IsIDRo, M., «El tiempo en el Reglamento 650/2012: Ilustraciones de la práctica española», REDI, vol. 70, 2018, núm. 2, pp. 127-154.

${ }^{34}$ La recomendación es del Parlamento y se publica en SALM, C., op. cit., nota 20, p. 17. Diversos autores analizan este movimiento hacia la «comunitarización» de este sector del Derecho privado: FRANZINA, P., «La protección internacional de adultos vulnerables: un llamamiento a la acción a nivel de la Unión Europea», AEDIPr, vol. XVI, 2016, pp. 127-145; PeREÑA VICENTE, M., «La libre circulación de las personas protegidas en Europa: la voluntad de la persona en la determinación de la ley aplicable a su protección», RCDI, 2018, núm. 767, año 94, pp. 1287-1325.

35 Adroher Biosca, S., op. cit., nota 21.

${ }^{36}$ Resolución del Parlamento Europeo, de 18 de diciembre de 2008, con recomendaciones destinadas a la Comisión sobre la protección jurídica de los adultos: implicaciones transfronterizas [2008/2123(INI)].
} 
recordar que existen otras medidas de protección que no revisten carácter judicial. Se trata, fundamentalmente, de los acogimientos familiares de personas mayores regulados en algunas normas autonómicas españolas ${ }^{37}$. Se trata de una medida de protección del ámbito de los servicios sociales de atención especializada que naturalmente puede alcanzar también a los mayores extranjeros que viven en nuestro país ${ }^{38}$.

10. Abordando la cuestión central de la competencia judicial internacional de los tribunales españoles en la materia, debe advertirse previamente de la naturaleza jurídica de los procesos de modificación de la capacidad y nombramiento de tutor, como procesos de jurisdicción voluntaria (tal y como se recoge en los arts. 43 a 55 de la Ley 15/2015), si bien, si se suscita oposición, el expediente se hará contencioso (art. 49). Por ello difícilmente serían operativos en estos casos los foros de competencia judicial internacional previstos en la LOPJ calificados doctrinalmente como «generales» al no existir ni partes ni demandado ${ }^{39}$, siendo únicamente relevantes el foro especial general, y el cautelar.

11. Las normas que recogen estos foros han sido modificadas en la reforma de la LOPJ operada por la Ley 16/2015 si bien se trata de una mera modificación terminológica; el foro competencial especial general se recoge en el art. 22 quater ${ }^{40}$. La única Resolución judicial analizada que aplica este precepto es el Auto del JPI núm. 13 de Valencia de 10 de noviembre de 2014, que resuelve sobre una demanda de incapacitación de una española residente en Bélgica, presentada por su hijo y concluye con la incompetencia judicial internacional de la jurisdicción española ${ }^{41}$.

37 Ley catalana 11/2001, de 13 de julio, de acogida familiar para personas mayores (DOGC, 24 de julio de 2001); Ley foral navarra 34/2002, de 10 de diciembre, de acogimiento familiar de personas mayores (BON, 13 de diciembre de 2002); Decreto 38/1999, de 8 de julio, por el que se regula el programa de acogimiento familiar para personas mayores del Principado de Asturias (BOPA, 2 de agosto de 1999); Decreto gallego 184/2000, de 29 de junio, por el que se modifica el Decreto 225/1994, de 7 de julio, de programa de acogimiento familiar para personas mayores y minusválidos (DOG, 13 de julio de 2000). Puede verse un estudio crítico de esta normativa en CARBAJO GonZÁLEZ, J., "Consideraciones críticas en torno al acogimiento de mayores en España», en CuEna CaSAS, M., ANGUita Villan, E. y ORtega Domenech, J. (coords.), Estudios de Derecho civil en homenaje al profesor Joaquin José Rams Albesa, Madrid, Dykinson, 2013.

38 Durán Ayago, M. A., "Nuevos escenarios en la protección internacional de los adultos», en Alonso Pérez, M., Martínez Gallego, E. y Reguero Celada, J., Protección jurídica de los mayores, Madrid, La Ley, 2004, p. 469. Más recientemente, CALDERÓN CoRREdor, Z., «El acogimiento familiar de adultos con discapacidad: la experiencia canadiense, Marco jurídico comparado e incentivos fiscales», RCDI, 2018, núm. 768, año 94, pp. 2061-2081.

39 Si bien legalmente el demandado es la persona vulnerable (véase art. 758 LEC), esta criticable e incoherente previsión legal será muy probablemente susceptible de reforma.

40 Antes el supuesto de hecho se definía de la manera siguiente: «Incapacitación y de medidas de protección de la persona o de los bienes de los menores o incapacitados». Ahora se refiere a esta materia de la manera siguiente: «La capacidad de las personas, y las medidas de protección de las personas mayores de edad y sus bienes».

41 Amablemente facilitado por el magistrado juez que lo dictó, D. José Miguel Bort Ruiz. En el Auto se señala: «Siendo así que la demandada presunta incapaz tiene su residencia habitual en Bélgica [...], no es posible entonces otra cosa, por razón de incompetencia de los tribunales españoles, que la inadmisión a trámite de la demanda de incapacitación que ha dado origen al presente procedimiento, y ello tanto por imperativo de lo dispuesto en los números $2 .^{\circ}$ y $3 .^{\circ}$ del art. 22 de la Ley Orgánica del 
Junto a este foro especial general, el foro especial «cautelar» está regulado en el art. 22 sexties. En los casos de protección de adultos, la calificación del concepto jurídico utilizado de «medidas provisionales y de aseguramiento» podría referirse a medidas tales como el internamiento no voluntario por razón de trastorno psíquico o el nombramiento de defensor judicial, entre otras $^{42}$. En relación al internamiento no voluntario por razón de trastorno psíquico pueden darse supuestos de falta de correspondencia entre el foro de competencia judicial internacional y el de competencia territorial. Los tribunales españoles son competentes por el mero hecho de que la persona se halle en territorio español, y, sin embargo, el art. 763 de la LEC señala la competencia territorial del tribunal del lugar donde resida la persona afectada por el internamiento. ¿Qué sucede si la persona todavía no reside en España y sin embargo debe adoptarse tal medida de protección en nuestro país? Claramente en estos casos deberá considerarse juez territorialmente competente el del lugar donde se halle dicha persona (aunque todavía no tenga allí su residencia) para no vulnerar el derecho a su tutela judicial efectiva.

12. Finalmente, la nueva regulación del foro de necesidad prevista en el art. 22 octies de la LOPJ justifica la competencia judicial internacional de las autoridades españolas en el caso de un extranjero que se encuentre en España en situación de vulnerabilidad y no sean aplicables los foros anteriormente analizados ${ }^{43}$, si bien con los límites previstos en esta nueva regulación (la exigencia de que el resto de tribunales conectados «haya declinado su competencia») que minimizan su operatividad.

13. En contraste con la regulación española, el HAPC prevé un foro general en la materia (autoridades de la residencia habitual del adulto y en caso de cambio de residencia, las autoridades del Estado de la nueva residencia habitual ex art. 5), y diversos foros alternativos y especiales ${ }^{44}$. Esta regulación es

Poder Judicial [...] como por aplicación de lo previsto en el art. 759.1 de la Ley de Enjuiciamiento Civil, que exige con carácter esencial en todos los procedimientos de incapacitación que el tribunal examine por sí mismo al presunto incapaz, lo que, desde luego, no será nunca posible si este reside fuera de España».

${ }_{42}$ Cuestión esta con importantes repercusiones en orden a los derechos fundamentales que están en juego y que han sido abordadas por la Circular 2/2017, de la Fiscalía General del Estado sobre el ingreso no voluntario urgente por razón de transtorno psíquico en centros residenciales para personas mayores que, sin embargo, no aborda las cuestiones derivadas de la extranjería de la persona mayor.

${ }^{43}$ EchezarReta FerRer, M. T., «Gestión de la diversidad y de la pluriconexión jurídica. Respuesta del Derecho internacional privado español a la protección de los Gic en situación de vulnerabilidad», en EchezARReta Ferrer, M. T. (dir.), El lugar europeo de retiro. Indicadores de excelencia para administrar la geronto inmigración de ciudadanos de la Unión Europea en municipios españoles, Granada, Comares, 2004, p. 364.

${ }_{44}$ Autoridades del lugar en el que se encuentre la persona (en caso de refugiados, desplazados y personas con residencia habitual indeterminada $e x$ art. 6); autoridades de su nacionalidad si consideran que están en mejores condiciones para valorar el interés del adulto, y después de comunicarlo a las autoridades competentes anteriores, salvo que estas hayan tomado ya medidas de protección o hayan decidido que no deben tomarse (ex art. 7); y autoridades de su nacionalidad, de su anterior residencia habitual, del lugar donde se encuentran sus bienes, del lugar a cuya protección se ha sometido por escrito el adulto, del lugar de la residencia habitual de la persona más allegada dispuesta a encargarse de él o del lugar en que se encuentre, si las autoridades de los arts. 5 o 6, consideran que en interés del adulto es 
mucho más flexible que la española, incorpora, para algunos, un forum non conveniens en el art. $8^{45}$ y se completa con un catálogo de normas especiales en los arts. 9-12. Sin embargo, se ha advertido la carencia de que no incorpora un foro electivo para el supuesto de las medidas ex ante, permitiendo al adulto extender su autonomía de voluntad también al ámbito jurisdiccional ${ }^{46}$. Por tanto, si España ratificara el HAPC, algunos de los problemas puestos de relieve en relación a la regulación vigente, tendrían una regulación más adecuada.

\section{DERECHO APLICABLE}

\subsection{Medidas ex ante}

14. En relación al Derecho aplicable, la primera cuestión a abordar es la relativa a las medidas ex ante, que cada vez van cobrando más relevancia en Derecho comparado como expresión de la autonomía de la voluntad; el propio ordenamiento jurídico español prevé la autotutela (arts. 223, 234 y 239 del CC) y las instrucciones previas (art. 11 de la Ley 41/2002, de 14 de noviembre, básica reguladora de la autonomía del paciente).

Un reciente trabajo analiza la ley aplicable a estas medidas ex ante ${ }^{47}$, y habida cuenta de la inexistencia de una norma de conflicto específica en la materia, especula sobre la calificación de los poderes o mandatos de representación otorgados en el extranjero (denominados como mandat d'inaptitude, springing power of attorney, entre otros), bien como representación legal, bien como voluntaria o bien como medida de protección acordada en otro Estado. En los dos primeros casos las normas de conflicto aplicables serían las previstas en el art. 10.11 del CC, en el tercero, el art. 9.6.2 del CC. A mi juicio esta última solución que introdujo el legislador español en 2015 prevé, precisamente el reconocimiento en España de las medidas de protección acordadas en otros Estados es la más consistente. Como señalaré en el siguiente epígrafe, debe realizarse una interpretación amplia del concepto «protección de adultos» incluyendo en él también las medidas de «autoprotección». Nuestro

\footnotetext{
más adecuado que las autoridades señaladas adopten todas o determinadas medidas de protección, así se lo requieran y ellas lo acepten (ex art. 8).

45 González Beilfuss, C., "La protección de adultos en Derecho internacional privado», en CALvo Caravaca, A. L. e Iriarte Ángel, J. L., Estatuto personal y multiculturalidad de la familia, Madrid, Colex, 2000, p. 96, lo cual se justifica en la posibilidad de cooperación entre autoridades de Estados contratantes. Para otros autores (Vicente Blanco, D. F. J., «La protección de los adultos en el derecho internacional privado codificado por la Conferencia de La Haya: el Convenio de 13 de enero de 2000 y sus soluciones», Oñati socio-legal series, vol. 1, 2011, núm. 8, pp. 9-10), sin embargo, no cabe calificar este mecanismo convencional como fórum non conveniens, entre otras razones porque hay un numerus clausus de autoridades susceptibles de ser consideradas «mejor competentes» para inhibirse a favor de la autoridad previamente considerada competente por el Convenio y el juez no debe apreciar criterios de «conveniencia», sino si tal atribución de competencia redunda «en interés del adulto».

46 Curry-Sumner, I., op. cit., nota 20, p. 63.

47 Pereña Vicente, M., op. cit., nota 34, p. 1317.
} 
legislador se ha inspirado en el propio HAPC que precisamente excepciona en este caso la aplicación de la ley de la residencia habitual. Otra cosa será el reconocimiento judicial o notarial de estos poderes o los efectos registrales de los mismos a los que aludiré en el epígrafe relativo al reconocimiento.

En todo caso, en relación a estas medidas, tendría un positivo efecto para España la ratificación del HAPC ${ }^{48}$. Sus arts. 15 y 16 regulan la ley aplicable al «mandato de protección», "de incapacidad» o «en previsión de incapacidad» del adulto. Si bien establecen como ley aplicable a la existencia, alcance, modificación y extinción de estos poderes la de la residencia habitual en el momento de otorgarlos, se establece la salvedad de que el adulto hubiera elegido expresamente como aplicable otra ley de entre un conjunto de leyes enumeradas: la de su nacionalidad, la de su anterior residencia habitual o la de un Estado en cuyo territorio se encuentren bienes de su propiedad. Además, prevé que las modalidades de ejercicio de tales poderes de representación se rijan por la ley del Estado en el que se ejerciten.

\subsection{Medidas ex post}

15. En relación a las medidas ex post, y una vez determinada la competencia judicial internacional de las autoridades españolas para modificar la capacidad de la persona y en su caso para adoptar una determinada medida de protección, analizaré el Derecho aplicable, tanto a la modificación de la capacidad como a las medidas de protección.

16. La protección ex post se determina en el art. 9.6 del CC, modificado por Ley 26/2015. Son dos las grandes novedades que presenta este artículo: la modificación del supuesto de hecho y el cambio del punto de conexión.

La primera es el cambio sustancial en la redacción del supuesto de hecho que ha pasado de ser la «tutela y demás instituciones de protección del incapaz» a la "protección de las personas mayores de edad». Se trata de un supuesto de hecho más abierto y amplio que el anterior y que evita los problemas de calificación que el anterior generaba ${ }^{49}$.

En primer lugar, antes solo se contemplaba la protección de aquellos mayores que fueran «incapaces» $y$, como he señalado, en Derecho comparado cada vez son más frecuentes las medidas de protección administrativas y es más excepcional la modificación de la capacidad o la incapacitación.

En segundo lugar, el supuesto de hecho anterior solo se refería a las medidas de protección, destacando a la tutela entre ellas, y sin embargo se había considerado que la modificación de la capacidad o incapacitación no estaba expresamente recogida en el supuesto. La nueva redacción integra ambos

\footnotetext{
48 Curry-Sumner, I., op. cit., nota 20, p. 64.

49 Calvo Caravaca, A. L. y Carrascosa Rodríguez, J., Derecho internacional privado, vol. II, Granada, Comares, 2016, p. 73.
} 
aspectos ya que, tanto la modificación de la capacidad como la adopción de una medida de protección, se engloban dentro del concepto «protección de personas mayores de edad», siguiendo en este punto el concepto amplio del término utilizado por el art. 3 del HAPC al que me refería en el epígrafe anterior en relación a las medidas ex ante. Carece de sentido considerar que la ley que regula la modificación de la capacidad sigue siendo la nacional en virtud del art. 9.1 del CC y sin embargo, la de la residencia habitual regula las medidas concretas de protección en aplicación del nuevo art. 9.6 CC $^{50}$; esta dualidad generaría numerosos problemas de armonización y adaptación ${ }^{51}$ y no está alineada con las tendencias modernas en materia de protección de menores y mayores que buscan una identificación fórum y ius, basados, además en el principio de proximidad que representa el foro (y la ley) de la residencia habitual ${ }^{52}$. La intención del legislador de 2015 fue claramente la de unificar ambas cuestiones en torno a la residencia habitual ${ }^{53}$.

17. El Anteproyecto de ley por la que se reforma la legislación civil y procesal en materia de discapacidad de 2018 vuelve a modificar el art. 9.6 únicamente en lo que al supuesto de hecho la norma se refiere, sustituyendo

50 No se ha entendido así por parte de algunos jueces que con la nueva redacción vigente han considerado que la modificación de la capacidad se rige por la ley nacional (en virtud de que el art. 9.1 señala la aplicación de esta ley a la capacidad), mientras que la tutela o curatela se rigen por la ley de la residencia habitual en virtud del art. 9.6. Así se advierte en la Sentencia del Juzgado núm. 95 de Madrid de fecha 29 de junio del 2018, dictada en un procedimiento de modificación de la capacidad de obrar (sentencia amablemente facilitada por la magistrada M. ${ }^{a}$ Dolores Ruiz). Se promueve a instancia de un hijo, respecto de su madre de noventa años con deterioro cognitivo avanzado la cual ostenta la nacionalidad francesa, si bien lleva más de sesenta años viviendo en Madrid. Otros dos hijos se han opuesto a la designación de tutor del demandante. En el FD 4 se señala: «El art. 9.1 del Código Civil establece que la ley personal correspondiente a las personas físicas es la determinada por su nacionalidad. Dicha ley regirá la capacidad y el estado civil, los derechos y deberes de familia la sucesión por causa de muerte. Y en el apartado 6 "la ley aplicable a la protección de las personas mayores de edad se determinará por la ley de su residencia habitual. En el caso de cambio de la residencia a otro Estado, se aplicará la ley de la nueva residencia habitual, sin perjuicio del reconocimiento en España de las medidas de protección acordadas en otros Estados. Será de aplicación, sin embargo, la ley española para la adopción de medidas provisionales o urgentes de protección".

En este caso Doña [...] es de nacionalidad francesa. Se ha indicado en la demanda la normativa aplicable del Código civil francés, en aplicación del art. 281 de la LEC. La normativa se aporta en francés, traducidas al castellano sin el visado de un intérprete, en la vista de juicio. El articulado que cita en la demanda no se corresponde con el articulado aportado en la vista. Siendo en todo caso un tema que no se ha visto cuestionado. Que las normas de protección como en este caso es la tutela y demás medidas, según nuestro código civil viene determinado por las normas del lugar de residencia, que en este caso es Madrid. Y asimismo partiendo de la normativa francesa aportada, aplicable para determinar en qué condiciones según la legislación francesa puede ser modificada la capacidad de obrar y las figuras de protección, no hay diferencias esenciales entre tal legislación y la española.

Esta posición judicial puede explicarse porque algún autor sigue considerando que la ley aplicable a la modificación de la capacidad o incapacitación esta prevista en el art. 9.1 CC, si bien las "medidas" de protección están reguladas en el art. 9.6» (CAlvo CaravaCA, A. y CARrascosa Rodríguez, J., nota 49, op. cit., p. 72).

51 Muñoz Fernández, A., La protección del adulto en el Derecho Internacional Privado, Navarra, Thomson Aranzadi, 2009, ya lo puso de relieve años antes de la reforma de 2015.

52 Borrás Rodríguez, A., «La protección internacional del niño y del adulto como expresión de la materialización del Derecho Internacional Privado: similitudes y contrastes», Pacis Artes. Obra homenaje al profesor Julio D. González Campos, vol. 2, Madrid, Editer, 2005, pp. 1287-1308.

53 Exposición de Motivos de la Ley 26/2015. 
«la protección de personas mayores de edad» por «las medidas de apoyo para personas con discapacidad», reiterando la sustitución del término protección por el de apoyo en el segundo y tercer párrafo. Probablemente la modificación aparentemente terminológica, responda al espíritu de la reforma civil basada, precisamente, en las medidas de apoyo como mecanismo jurídico fundamental en estos casos. Además, la nueva redacción incluiría no solo a los adultos sino también a los menores necesitados de una medida de apoyo.

Sin embargo, dado que existen sistemas jurídicos en el mundo que se adscriben al modelo tradicional (como es el español vigente) que se basa en la modificación de la capacidad primero y la adopción de una medida de protección después, y dada la pervivencia del art. 9.1 del CC que determina la ley aplicable a la capacidad, esta reforma podría generar un efecto seguramente no deseado; los jueces españoles deberían aplicar en algunos casos y respecto de extranjeros procedentes de determinados países, su ley nacional para modificar su capacidad y la española para adoptar la medida de apoyo.

Considero conveniente mantener la redacción actual del supuesto de hecho que, por otra parte, coincide con la prevista en el HAPC y es la utilizada en los más recientes documentos de la UE. No parece que utilizar el término «protección» en relación a las personas con discapacidad pueda calificarse de paternalista.

18. La segunda novedad de esta norma en 2015 es la sustitución del punto de conexión de la nacionalidad por el de la residencia habitual, en línea con lo establecido en el HAPC, cambio que la doctrina celebra como muy positivo ${ }^{54}$. Con ello, se evitan, además, problemas de aplicación frecuentes en el pasado, tales como la aplicación de la cláusula de orden público, el reenvío o la prueba del Derecho extranjero. Por otra parte, en el segundo párrafo se incluye una regla que resuelve el eventual conflicto móvil que puede plantearse, y que, como se verá en alguna sentencia en la que se producen traslados posteriores al país de origen, no es, en absoluto, infrecuente ${ }^{55}$. Los tribunales ya están aplicando esta nueva norma legal, incluso en relación a casos a los que era aplicable la anterior normativa ${ }^{56}$, si bien con algunas excepciones ${ }^{57}$.

54 GuZmán Zapater, M., «Persona física», en Abarca Junco, P. et al., Derecho internacional privado, Madrid, UNED, 2016, p. 426; Calvo Caravaca, A. L. y Carrascosa Rodríguez, J., op. cit., nota 49, p. 73; Álvarez Torné, M., op. cit., nota 30, p. 16; Muñoz FernÁndeZ, A., op. cit., nota 18, pp. 289 y 295.

55 «En la sociedad líquida y móvil del siglo XXI, esta regla especial fija de un modo dinámico la ley aplicable a la protección de los mayores de edad» (CAlvo CARAVACA, A. L. y CARrascosa Rodríguez, J., op. cit., nota 49, p. 73).

56 Es el caso de la Sentencia de la AP de Barcelona (Sección 18. ${ }^{\text {) }}$ núm. 826/2016, de 2 de noviembre (JUR 2018/19660), de la que es ponente la magistrada Dolores Viña Farré y en la que se señala en relación a la tutela de un menor de nacionalidad marroquí: «Y finalmente cabe tener en cuenta en esta alzada la modificación del art. 9.6 CC introducida por Ley 26/2015, de 28 de julio, que establece ahora que la ley aplicable a la protección de mayores de edad se determinará por la ley de su residencia habitual, por lo que hay que estar a lo dispuesto en el art. 222-10 CC».

57 Es el caso de la Sentencia de la AP de Barcelona (Sección 18. ${ }^{\text {a }}$ ) núm. 70/2017, de 31 de enero (JUR 2018/26821), en la que, sin embargo, acaba aplicando el Derecho español al ser un caso de doble nacionalidad: «A la fecha de interposición de la demanda, la afectada, D. ${ }^{\mathrm{a}}$ Dulce, de nacionalidad doble, española y peruana, tenía su residencia en esta ciudad. [...]. La Ley aplicable es la española. El art. 9.6 
También lo ha hecho la DGRN en una reciente Resolución que acoge favorablemente la reforma ${ }^{58}$, reforma que en este punto no ha sido objeto de modificación por el Anteproyecto mencionado.

Persiste, sin embargo, la diferencia entre las medidas protectoras y las urgentes, y cabe plantear alguna dificultad de calificación ya que una misma medida puede tener carácter urgente, provisional y protector ${ }^{59}$. En relación al ámbito de la ley aplicable, parece más adecuado entender que la legitimación para promover la medida de protección es de carácter procesal y, por tanto, debe aplicarse a ella el Derecho español (art. 3 LEC).

19. La ratificación del HAPC también aportaría importantes novedades en relación a la ley aplicable. Aunque la regla básica del Convenio es la lex auctoritatis (que es precisamente la de la residencia habitual recogida ahora en nuestro CC, al ser la residencia habitual el foro de competencia judicial internacional) la solución es matizada por la aplicación de la ley más estrechamente vinculada en interés del mayor (art. 13.1) ${ }^{60}$. Junto a la excepción ya analizada relativa a las medidas ex ante en el art. 15, se establece una precisión en relación a la eficacia extraterritorial de la medida en el art. 14. En definitiva, como se ha señalado, la norma convencional contribuiría a consolidar la autonomía de la voluntad en la materia ${ }^{61}$.

20. En conexión con los problemas de determinación del Derecho aplicable, se plantean las cuestiones registrales. En Derecho español, a diferencia

y 9 CC la determinan en razón de la nacionalidad del presunto incapaz y, de tener varias de la nacionalidad, la ley a aplicar es la coincidente con la última residencia. El alcance de la incapacitación se rige por la ley estatal (art. 200 CC), pero los mecanismos de protección a aplicar son los del Codi civil de Catalunya (CCCat), conforme al principio de territorialidad y a falta en los autos de ningún elemento de conexión con cualquier otro marco normativo en el momento de la demanda (arts. 14.1 del Estatut d'Autonomia de Catalunya y 111.3.1 del Codi Civil de Catalunya». Es también el caso de la Sentencia de la AP de Las Palmas de Gran Canaria (Sección 4. a) núm. 2015/385, de 15 de octubre (JUR 2016/23937) que, sin embargo, no pudo aplicar esta nueva normativa por razones de Derecho transitorio y que señala: «De conformidad con lo dispuesto en los arts. 9.1 y 9.6 CC la capacidad y la tutela de la demandada se rigen por su ley nacional, la ley austriaca, y por tanto, es persona incapacitada en los términos y con el alcance antes consignado».

58 Resolución DGRN núm. 4712/2018, de 23 de marzo (RJ 2018/1886): «La norma de conflicto no resulta del apartado 1 del artículo 9 del Código Civil que conduce a la nacionalidad del representado, sino que está constituida por el apartado 6 de dicho artículo (en redacción dada por Ley 26/2015, de 28 de julio, de modificación del sistema de protección a la infancia y a la adolescencia). Conforme a esta, en lo que ahora interesa, la ley aplicable a la protección de las personas mayores de edad se determinará por su residencia habitual. Con ello coincide —en cuanto a esta regla principal- con el Convenio de La Haya de 13 de enero de 2000 sobre Protección Internacional de los Adultos del que España no es parte (véase sobre la laguna existente en el Derecho de la Unión Europea, la Resolución del Parlamento Europeo de 1 de junio de 2017)».

59 Echezarreta Ferrer, M. T., op. cit., nota 43, p. 359.

60 Como se ha señalado, debido a que, en contraste con los menores, en el caso de los mayores, junto con la protección de la persona tiene un peso específico, también, la protección de sus bienes, «el interés del adulto» no tiene el carácter superior, sino que es uno de los criterios a tomar en consideración, relevante pero no siempre determinante (VicENTE BLANCo, D. F. J., nota 45, op. cit., p. 7). Sin embargo, diversas sentencias se refieren al interés superior del incapaz. La más reciente la Sentencia del Tribunal Supremo (Sala de lo Civil, Sección 1.a ) núm. 458/2018, de 18 de julio (RJ 2018/2957).

61 Álvarez Torné, M., op. cit., nota 30, p. 16; Pereña Vicente, M., op. cit., nota 34. 
de otros sistemas jurídicos, el juez debe inscribir de oficio la resolución judicial en el RC. Ya se analizaron doctrinalmente los problemas prácticos a que daba lugar la vigente regulación registral ${ }^{62}$. A tenor de la Ley 20/2011, de 21 de julio, del Registro Civil (aún no en vigor), en los casos en los que el juez haya modificado la capacidad, esta debe inscribirse en el registro individual del afectado (art. 72) y lo mismo sucede con las tutelas y curatelas (art. 73). Por otra parte, no existe obligación de dar traslado de la información al RC de nacimiento del interesado, salvo que un convenio internacional señale otra cosa. En esta materia debe destacarse el Convenio de la CIEC relativo al intercambio internacional de información en materia de estado civil de 4 de septiembre de 1958 y su Protocolo de 6 de septiembre de $1989^{63}$. La información que debe enviarse obligatoriamente es la relativa al matrimonio y a la defunción, si bien «lo dispuesto en los artículos precedentes no impedirá la transmisión a las autoridades de un Estado contratante por vía diplomática y otra vía prevista por algún Convenio en concreto para cualquier acto o decisión relativos al estado civil de una persona nacida en el territorio de ese Estado» (art. 4).

21. Finalmente, y como señala una reciente sentencia, la solución prevista en el art. 9.6 debe aplicarse también para determinar el Derecho aplicable en casos de conflictos de leyes dentro de España ${ }^{64}$.

\section{RECONOCIMIENTO Y EFICACIA DE DECISIONES JUDICIALES EXTRANJERAS Y DE DOCUMENTOS PÚBLICOS EXTRANJEROS}

22. La tercera cuestión que debe plantearse es el reconocimiento en España de modificaciones de capacidad, tutelas, curatelas u otras medidas de protección constituidas en el extranjero, así como de poderes o mandatos de representación otorgados fuera de España.

${ }^{62}$ En relación a la incapacitación, debe inscribirse al margen de la inscripción de nacimiento (art. 46 de la LRC) pero al ser el incapacitado extranjero no nacido en España, debe promoverse antes una inscripción de nacimiento fuera de plazo en el RC Central que sirva de soporte a la marginal (art. 15 LRC). En relación a la tutela, el problema es el de determinar cuál es el Registro competente, sobre todo en casos de cambio de domicilio, dado que art. 89 de la LRC señala que «las inscripciones relativas al organismo tutelar se practicarán en el Registro del domicilio de las personas sujetas a la tutela en el momento de constituirse esta». Existe una necesidad de correspondencia entre el juez competente en el procedimiento de tutela o incapacitación y el RC, y por ello en la práctica se está inscribiendo en el RC de la residencia habitual que es el del juez territorialmente competente (ADROHER BioscA, S., op. cit., nota 21).

${ }^{63} B O E$ núm. 173, de 21 de junio de 1994, y núm. 174, de 22 de julio de 1994. Se trata de un convenio inter-partes ratificado por Alemania, Austria, Bélgica, España, Francia, Italia, Luxemburgo, Países Bajos, Polonia, Portugal y Turquía.

${ }^{64}$ Así lo recoge la Sentencia de la AP de Barcelona (Sección 18. ${ }^{\text {a }}$ ) núm. 466/2017, de 24 de mayo (JUR 2017/198597): «En cuanto al nombramiento del Administrador Patrimonial, y en cuanto a la alegación de la Asistencia Letrada del Sr. Arsenio, hay que tener en cuenta que el art. 9.6 Código Civil, al que se remite el art. 16 para resolver los conflictos de leyes interterritoriales, en su redacción vigente en el momento del dictado de la sentencia que es cuando se acuerda el nombramiento de tutor, según reforma por Ley 26/2015, de 28 de julio, se remite a la Ley de residencia habitual. Es de aplicación, por tanto, la legislación de Cataluña». 
Lo primero que debe recordarse, dada la primacía del Derecho UE, es que ningún Reglamento comunitario, singularmente los denominados Bruselas I bis y II bis, incluyen esta cuestión en su ámbito de aplicación ${ }^{65}$. Sí lo hacen, sin embargo, algunos Convenios internacionales bilaterales, en particular los firmados con Austria, Alemania y Rusia que prevén un sistema de reconocimiento directo de las sentencias extranjeras sin necesidad de procedimiento especial alguno respecto de los efectos constitutivo y de cosa juzgada ${ }^{66}$. En caso de no ser de aplicación estos convenios por no provenir la resolución de uno de estos países, será aplicable el sistema estatal, pero para determinar la norma en la que se encuadra el régimen de reconocimiento, es importante realizar una calificación previa de la naturaleza contenciosa o voluntaria de la decisión extranjera cuyo reconocimiento se solicita, así como del efecto pretendido.

En el caso de que la resolución extranjera tenga naturaleza contenciosa, el Derecho interno español prevé, desde 2015 el reconocimiento directo o incidental de las resoluciones judiciales extranjeras respecto de todos sus efectos, salvo el ejecutivo, para el que sigue siendo necesario el exequatur. Así, con carácter general lo establece el art. 55 de la LCJIMC y en este mismo sentido la nueva LRC en su art. 96, prevé el «efecto registral» directo sin que sea preciso un previo exequatur.

En el caso de que la decisión o resolución extrajera se califique de «jurisdicción voluntaria», como habitualmente se considera la constitución de una tutela en Derecho comparado, el régimen aplicable al reconocimiento será el previsto en el art. 12 de la nueva LJV que básicamente sigue el esquema de la LCJIMC que acabo de señalar.

65 Sin embargo, una Sentencia de la AP de Las Palmas de Gran Canaria (Sección 4. a) núm. 385/2015, de 15 de octubre (JUR 2016/23937) aplica de manera inadecuada el Reglamento Bruselas II bis [Reglamento (CE) núm. 2201/2003, del Consejo, de 27 de noviembre, relativo a la competencia, el reconocimiento y la ejecución de resoluciones judiciales en materia matrimonial y de responsabilidad parental, por el que se deroga el Reglamento núm. 1347/2000] para reconocer de forma directa una resolución austriaca de incapacitación y nombramiento de tutor: «El mencionado Auto judicial austriaco tiene plena eficacia en España ipso iure, sin necesidad de recurrir a procedimiento alguno, conforme a los arts. 1-2 y 21 del Reglamento 2201/2003 del Consejo, de 27 de noviembre, y arts. 32 y 33 del Reglamento (CE) 44/2001, de 22 de diciembre, acerca del reconocimiento sin necesidad de recurrir a procedimiento alguno, al tratarse de una resolución judicial en materia civil, dictada por un Tribunal de un Estado miembro de la Unión Europea». Si bien el art. 1.2 de este Reglamento al establecer su ámbito de aplicación se refiere a «la tutela, curatela y otras instituciones análogas» es evidente que estas van referidas a la «responsabilidad parental» que solo puede predicarse en menores de edad, tal y como recoge el considerando 5 del propio Reglamento.

${ }_{66}$ Así se señala en el Auto de reconocimiento dictado por el JPI núm. 13 de Valencia el 17 de enero de 2012 (amablemente facilitado por el magistrado juez que lo dictó, José Miguel Bort Ruiz) y que señala: «De conformidad con lo dispuesto en los arts. 85-5 de la Ley Orgánica del Poder Judicial y 951, 955 y 956 de la Ley de Enjuiciamiento Civil de 1881, en relación a lo pactado en el Convenio de 14 de noviembre de 1983 celebrado entre el Reino de España y la República Federal de Alemania sobre reconocimiento y ejecución de resoluciones y transacciones judiciales y documentos públicos con fuerza ejecutiva en materia civil y mercantil, es procedente acceder al interesado reconocimiento de las resoluciones judiciales alemanas a que se contrae el expediente, al constar la concurrencia en ellas de todos los requisitos esenciales cuya falta autorizaría, según el convenio, la denegación de dicho reconocimiento». 
Este nuevo sistema de reconocimiento indirecto, y la no necesidad del exequatur, no ha sido todavía comprendido ni aplicado por nuestras autoridades administrativas en todos los $\operatorname{casos}^{67}$.

24. También pueden plantearse en esta materia solicitudes de reconocimiento de documentos públicos extranjeros distintos de las sentencias como son, singularmente, los poderes o mandatos de representación. En relación a ellos, los efectos registrales generales están contemplados en el art. 60 LCJIMC, pero es el art. 97 de la LRC el que prevé los requisitos concretos para que un documento extranjero extrajudicial tenga efectos registrales en España, y en el art. 98 regula el acceso al RC de certificaciones de asientos extendidos en Registros extranjeros. Si son estos efectos los que se pretenden, este será el cauce para su reconocimiento.

Sin embargo, puede ser que no se pretenda un efecto registral sino el mero reconocimiento de un documento público extranjero para algún tipo de efecto. Montserrat Pereña pone el ejemplo de un ciudadano francés que en previsión de su posible incapacidad otorga ante un notario francés un mandato de representación futura a favor de su hermano que ahora, esgrimiéndolo, pretende enajenar un bien inmueble que este tiene en España ${ }^{68}$. Serán los arts. 56 y 57 de la LCJIMC los aplicables a este caso, que incluyen el mecanismo de la adaptación, pero supuestos como este no tienen una respuesta satisfactoria en nuestro sistema jurídico.

Finalmente, puede haber casos en los que lo que se pretenda es la eficacia directa de uno de estos mandatos o poderes, y no solo a cuestiones patrimoniales, sino también a cuestiones personales que en ocasiones presentan urgencia extrema. Es muy expresivo el ejemplo que propone al respecto Ian Curry-Sumner en relación a la toma de decisiones médicas ${ }^{69}$.

${ }^{67}$ Así se advierte en la Resolución núm. 2/2015, de 11 de diciembre, de la DGRN (JUR 2016/215683). La sobrina del interesado y tutora del mismo en virtud de sentencia judicial cubana, solicita en su nombre la recuperación de su nacionalidad española. Se le deniega, y la DGRN señala al respecto: «La sentencia aportada por la que se reconoce a la sobrina del interesado tutora de este, es dictada por un tribunal extranjero, no teniendo fuerza suficiente para su inscripción en el Registro Civil español, debiendo previamente tramitarse exequatur para que, una vez obtenido el título suficiente, practicar la inscripción de incapacitación del Sr. E. P. y la toma de posesión del cargo de tutor/ tutora por parte de la persona designada al efecto. Una vez hechas estas actuaciones, la persona designada como tutor podrá iniciar el procedimiento legalmente establecido para la recuperación de la nacionalidad española por parte del incapacitado».

68 Pereña Vicente, M., op. cit., nota 34, pp. 1293 y ss.

69 "Ursula is a citizen of State A living in State B. She has appointed her brother to act as her representative in accordance with the law of State A. She is involved in a car accident in State B and is admitted to hospital. In order to be discharged, it is a requirement that the hospital have the discharge signed by her legal representative. The question is whether Ursula's brother is regarded as the legal representative, as this depends on whether State B will recognise the power of representation drafted in favour of Ursula's brother.

This situation would become even more poignant if the question to be posed was whether Ursula should be taken off life support. If the power of representation were to be recognised then Ursula's brother would be entitled to make these decisions. If the power of representation was not recognised, then the general provisions laid down in the applicable law would need to be utilised to determine who was responsible to make the respective decision» (CURRY-SUMNER, I., op. cit., nota 20, p. 71). 
25. El HAPC prevé un reconocimiento incidental de las medidas adoptadas en un Estado contratante. Se trata de un procedimiento simple y rápido de declaración de ejecutoriedad y registro, no procediendo el reconocimiento en los siguientes casos: autoridad incompetente, no audiencia del protegido, contrariedad con el orden público y contradicción con otra medida de protección. Sin embargo, tampoco en este punto el sistema convencional es eficaz del todo. Por ello, el Parlamento Europeo ha propuesto medidas específicas en la materia que incluyen la creación de un certificado europeo de poderes preventivos ${ }^{70}$.

\section{COOPERACIÓN INTERNACIONAL DE AUTORIDADES}

26. La cooperación de autoridades en esta materia puede plantearse ad extra o ad intra.

En relación al reconocimiento extraterritorial de una medida judicial adoptada en España respecto de un extranjero, son dos los problemas que se han suscitado en la práctica. Los casos relatados por jueces y magistrados suelen responder a medidas de protección adoptadas tras accidentes laborales o de tráfico sufridos por inmigrantes, a resultas de los cuales quedan en situación de extrema dependencia. Tras el reconocimiento de una pensión por invalidez y de los derechos económicos derivados de los seguros, se adopta una medida de protección judicial y un tiempo después, la familia decide desplazarse con el accidentado a su país de origen.

Por una parte, el juez se plantea cómo realizar el control de las funciones del tutor en caso de desplazamiento del tutelado y su tutor fuera de España ${ }^{71}$. La nueva LCJIMC regula por primera vez la cooperación jurídica internacional y en el art. 21 se prevé el cauce que el juez español deberá emplear en estos $\operatorname{casos}^{72}$.

Por otra, puede suceder que el juez español ha constituido una medida de protección y se solicita el traslado del protegido fuera de España y existen sospechas de que las funciones de la tutela no se ejercerán adecuadamente en su país. En estos casos, si bien de entre los actos del tutor para los que necesita autorización judicial no se encuentra la salida de España (art. 271 CC), cabría prohibirla de acuerdo con el art. 216 en relación con el art. 158 del CC. Así se recoge en una reciente sentencia que llega a referirse a esta situación como «sustracción internacional de mayores» ${ }^{73}$.

\footnotetext{
${ }^{70}$ Las propuestas relacionadas con este epígrafe son las siguientes: «Abolishing the requirement of the exequatur for measures of protection taken in EU Member States; creating a European certificate of powers granted for the protection of an adult» (SALM, C., nota 20, op. cit., pp. 4-5).

71 En aplicación de los arts. 269.4 y 271.5 del CC.

72 Un trabajo imprescindible sobre esta nueva Ley es el de RoDRíGUEz BENOT, A., «La ley de cooperación jurídica en materia civil», Cuadernos de Derecho transnacional, vol. 8, marzo de 2016, núm. 1, pp. 234-259.

${ }_{73}$ «La Sala denegó la petición de medidas cautelares por falta de peligro en la demora, al haberse producido el traslado a Perú seis meses antes de dictarse la resolución apelada (en julio de 2015) y con
} 
27. La otra situación que puede plantearse es la cooperación ad intra, en los supuestos en los que se ha adoptado una medida de protección en el extranjero, y la persona es desplazada a España. En la práctica forense se exponen casos de familias inmigrantes que priorizan en la reagrupación familiar al hijo o familiar con alguna discapacidad. Si el juez del país de origen pretende hacer un seguimiento de la tutela en España con la cooperación de un juez español, esta debe articularse a través del sistema de cooperación antes señalado.

28. Estas cuestiones, no resueltas de forma totalmente satisfactoria en el marco del ordenamiento jurídico español vigente, están contempladas, sin embargo, en el HAPC, tanto en el Capítulo IV relativo al reconocimiento y la ejecución como en el V relativo a la cooperación. Esta última se articula a través de la designación en los Estados parte de Autoridades centrales cuyas funciones básicas son facilitar las comunicaciones entre los Estados miembros, la localización de un adulto, la aplicación de medidas de protección, la transmisión de información en los casos en que el adulto se encuentre en grave peligro, etcétera.

Además, el Convenio contempla la cooperación de autoridades, para facilitar la continuidad espacial de la medida con dos previsiones. Por una parte, cada Estado podrá designar autoridades centrales con diversas funciones ${ }^{74}$; y por otra, se prevé la cooperación entre autoridades que adoptan las medidas de protección ${ }^{75}$. No obstante, debe advertirse que estas normas convencionales son de aplicación inter partes y, por tanto, no son susceptibles de aplicación en los casos en que el otro Estado con cuya autoridad se plantea la cooperación no es parte del Convenio. Por otra, las reglas de cooperación del Convenio no se han demostrado totalmente eficaces, son uno de sus puntos débiles y es por ello que el Parlamento Europeo ha planteado la necesidad de adoptar normas europeas precisamente en esta materia ${ }^{76}$.

conocimiento de los solicitantes de las medidas. El Convenio de Nueva York de 13 de diciembre de 2006, ratificado por España (BOE núm. 96, de 21 de abril de 2008) y por Perú, promueve en el art. 13 el acceso de las personas con discapacidad a la justicia, en el art. 18 proclama la libertad de desplazamiento y en el art. 19 recoge el derecho de las personas discapacitadas a elegir con libertad su residencia. No obstante, hubiera sido adecuado que la salida de la presunta incapaz del territorio nacional, pendiente el proceso de incapacitación, se hubiera sometido a autorización judicial previa, incluso para el caso de que se juzgara conveniente a su interés, permitiendo al tribunal oír a la incapaz y a los parientes y practicar las pruebas necesarias para convencerse que era conveniente a su interés. Aún más cuando la Sentencia apelada, en extremo que no ha sido apelado, limita su capacidad de D. ${ }^{a}$ Dulce para escoger el lugar donde ha de vivir y los viajes que puede realizar. Finalmente, la Sala aprecia, como se verá, que el traslado no fue ilícito. No podía el hijo guardador disponer sobre tal desplazamiento sin autorización judicial, aunque no se puede hablar de un supuesto de sustracción internacional, por no constar tal voluntad, ni legislación internacional al efecto». Sentencia de la AP de Barcelona (Sección 18. ${ }^{a}$ ) núm. 70/2017, de 31 de enero (JUR 2018/26821).

${ }^{74}$ Intercambio de información sobre su legislación y servicios en materia de protección de adultos; la adopción de medidas apropiadas para facilitar comunicaciones entre autoridades competentes; ayudar a localizar a un adulto que tiene necesidad de protección cuando parezca que se encuentra en su territorio, y apoyar la ejecución de las medidas adoptadas.

75 Información, asistencia para la ejecución de medidas y favorecer el recurso a la mediación, conciliación u otros medios de alcanzar acuerdos amistosos sobre la protección de los adultos.

${ }^{76}$ "Several weaknesses such as, for example, poor cooperation and communication among the authorities of the Contracting States, difficulties in carrying out foreign protective measures, and weaknesses 


\section{CONSIDERACIONES FINALES}

29. Bartin, positivista francés del siglo XIX consideraba al Derecho internacional privado como la «sombra» del Derecho sustantivo estatal, expresión o proyección de las categorías y principios del Derecho privado sobre las normas reguladoras del tráfico jurídico externo ${ }^{77}$. El sistema jurídico civil español relativo a la protección de adultos ha sufrido en 2015 algunas modificaciones con la entrada en vigor de la LJV y también algunas modificaciones terminológicas en otros cuerpos legales en los que el término y concepto «incapacitación» ha sido sustituido por el de «modificación judicial de la capacidad». Sin embargo, la gran reforma civil de la materia, derivada de la necesaria incorporación a nuestro ordenamiento jurídico de la CNUDPD está en marcha y «sería paradójico que esta intensa modernización de la legislación nacional y autonómica», no fuese acompañada de la ratificación por España de los instrumentos internacionales que regulan los aspectos transfronterizos de esta materia ${ }^{78}$.

30. A lo largo de estas páginas he analizado las modificaciones operadas en las normas de Derecho internacional privado en 2015; en algunas ocasiones han sido puramente terminológicas, como es el caso de la LOPJ, en otras de fondo, como es el caso del art. 9.6 del CC, en otras son, en fin, modificaciones generales como es el nuevo sistema de reconocimiento de resoluciones extranjeras recogido tanto en la LCJIMC como en la LJV que prevén un sistema de reconocimiento directo o incidental para gran parte de los efectos pretendidos ${ }^{79}$.

31. La novedad más relevante ha sido, sin duda, la nueva redacción del art. 9.6 del CC tanto en la formulación amplia de su supuesto de hecho, como la sustitución del punto de conexión de la nacionalidad por el de la residencia habitual para determinar la ley aplicable a la protección de adultos, que además alinea las normas de forum y ius ${ }^{80}$.

with regard to the ways in which evidence of the powers granted to a representative of a vulnerable adult are to be provided" (SALM, C., op. cit., nota 20, p. 4).

77 "Les régles de conflict sont des régles nationales dans chaque pays, au mème titre que les institutions de droir interne dont elles circonscrivent le domaine. Elles leur restent liées comme l'ombre au corps, parce que'elles ne sont autre chose que la projection de ces institutions elles-mèmes sur le plan international». BARTIN, E., "De l'impossibilité d'arriver à la solution définitive des conflicts de lois», JDI, 1897, pp. 225 y ss.

78 IrIARTE Ángel, J. L., op. cit., nota 31, p. 208; también Marchal Escalona, N., «Los límites de lo "real" y de lo "personal" en el sistema europeo de competencia judicial», La Ley Unión Europea, diciembre de 2014, p. 10.

79 De Salas Murillo, S., «Incidencia de la Ley de la Jurisdicción Voluntaria en la regulación relativa a las personas con discapacidad», en Areces PIÑol, M. T. (coord.), Nuevos modelos de gestión del derecho privado: jurisdicción voluntaria, Madrid, Dykinson, 2016, pp. 257-301.

${ }^{80}$ La Ley 26/2015 al modificar la normativa sustantiva española en materia de protección de menores, introdujo las reformas correspondientes en las normas de Derecho aplicable en materia de filiación, protección y alimentos (art. 9, párrs. 4, 5, 6 y 7 del CC), siguiendo los postulados del recordado Bartin que aconsejaba la necesaria coordinación entre las reformas sustantivas y las «conflictuales». Dado que el art. 9.6 regulaba, además, la protección de mayores de edad, se optó por modificarlo tam- 
Este cambio va a plantear, sin duda, cuestiones de calificación del concepto residencia habitual, que puede tener diverso alcance en el caso del colectivo de gerontomigrantes o del de inmigrantes más jóvenes. Sería demasiado largo analizar en este trabajo este concepto multidimensional y que, por otra parte, ha tenido diversas interpretaciones en función de la materia regulada, incluso en aplicación de los diversos Reglamentos UE que lo adoptan como criterio de conexión, tanto en materia matrimonial como sucesoria ${ }^{81}$. Serán los tribunales los que lo definan ante el caso concreto, pero siguiendo a Javier Carrascosa en su trabajo sobre el Reglamento de sucesiones, materia muy cercana a la estudiada ${ }^{82}$, podría señalarse que la residencia habitual es el lugar donde está el centro de vida de la persona tomando en consideración los datos de la realidad, con independencia de la residencia legal del Derecho de extranjería, de la residencia fiscal e incluso del empadronamiento ${ }^{83}$. Es evidente que los gerontoinmigrantes que eligen España como lugar de retiro tienen a nuestro país como centro de esta etapa final de su vida; pero también lo es que, gran parte de los inmigrantes que muchas veces llegan a España soñando con el mito del retorno, acaban instalándose para siempre entre nosotros.

La Sentencia del TJUE, Sala 3. ${ }^{\mathrm{a}}$, de 3 de octubre de 2013, dictada en el asunto C-386/12, Siegfried János Schneider, en la que un ciudadano húngaro sometido a curatela solicita autorización para vender la cuota indivisa de un bien inmueble sito en Bulgaria que había heredado tras el fallecimiento de su madre, pone de manifiesto que en muchos supuestos podrá ser difícil determinar la residencia habitual ${ }^{84}$.

32. He insistido a lo largo del trabajo en la importancia de la ratificación del HAPC que, a pesar de sus carencias, dotaría al sistema jurídico español de un instrumento moderno que mejoraría sustancialmente la regulación vigente en los cuatro sectores analizados ${ }^{85}$. De entre ellos, son quizá la regulación de las medidas ex ante y la cooperación internacional de autoridades, los ámbitos en los que, a pesar de las carencias señaladas del texto convencional,

\footnotetext{
bién en este punto, redactando una regla que recogiera el «espíritu» del HAPC a la espera de su firma, para la que se estaban solicitando ya los informes preceptivos. Puedo afirmar esto como responsable del órgano directivo de la Administración General del Estado que impulsó y coordinó la redacción de esta ley, Dirección General de Servicios para la Familia y la Infancia del Ministerio de Sanidad, Servicios Sociales e Igualdad.

81 Pueden verse los siguientes análisis al respecto: Pérez MARTín, L. A., «Determinación y trascendencia de la residencia habitual en las crisis familiares internacionales», en GUZMÁN ZAPATER, M. y Herranz Ballesteros, M. (dirs.), Crisis matrimoniales internacionales y sus efectos. Derecho español y de la Unión Europea. Estudio normativo y jurisprudencial, Valencia, Tirant lo Blanch, 2018, pp. 915-952 (en prensa); CARrascosa Rodríguez, J., «El concepto de residencia habitual del causante en el Reglamento sucesorio europeo», Barataria, Revista Castellano-Manchega de Ciencias Sociales, 2015, núm. 19, pp. 15-35.

82 CARrascosa Rodríguez, J., op. cit., nota 80.

83 Ya hemos visto al principio de este trabajo cómo los datos de permisos de residencia y de extranjeros empadronados no coinciden exactamente.

${ }^{84}$ Así lo expone Marchal Escalona, N., op. cit., nota 77.

85 Como señala Echezarreta FERrER, M. T., «Dimensión jurídica de las relaciones transfronterizas derivadas de la gerontoinmigración», REDI, vol. 70.2, 2018, pp. 223-229.
} 
esta ratificación supondría un avance más significativo en relación a la normativa estatal vigente.

Este convenio es paralelo en su filosofía al Convenio relativo a la competencia, la ley aplicable, el reconocimiento, la ejecución y la cooperación en materia de responsabilidad parental y de medidas de protección de los niños, hecho en La Haya el 19 de octubre de 1996, del que España es parte ${ }^{86}$; no en vano, ambos son la plasmación, en el ámbito del Derecho internacional privado, de las Convenciones de Naciones Unidas sobre derechos del niño y sobre derechos de las personas con discapacidad y como ha señalado recientemente la DGRN en ambos «instrumentos tuitivos, el principio orientador es el interés superior del niño o del adulto vulnerable» ${ }^{87}$.

\title{
RESUMEN
}

\section{LA PROTECCIÓN DE ADULTOS EN EL DERECHO INTERNACIONAL PRIVADO ESPAÑOL: NOVEDADES Y RETOS}

El régimen jurídico de la protección de adultos en el Derecho internacional privado español ha sufrido importantes modificaciones en cuatro leyes aprobadas en 2015: Ley Orgánica 7/2015 de modificación de la Ley Orgánica del Poder Judicial, la Ley 15/2015 de Jurisdicción Voluntaria, la Ley 26/2015 de Modificación del Sistema de Protección a la Infancia y a la Adolescencia, y la Ley 29/2015 de Cooperación Judicial Internacional en Materia Civil. La entrada en vigor de la reforma registral de 2011 se ha vuelto a retrasar hasta 2020. En este artículo se analizan las novedades que aportan estas reformas, a través del análisis de la jurisprudencia y doctrina administrativa que las aplica, pero se pone de manifiesto la urgente conveniencia de que España ratifique el Convenio de La Haya sobre protección internacional de adultos de 2000, que supondría un régimen jurídico más adaptado a las nuevas necesidades, sobre todo de cooperación, que el sector precisa.

Palabras clave: protección internacional de adultos, competencia judicial internacional, Derecho aplicable, reconocimiento de decisiones extranjeras, Convenio de La Haya sobre protección internacional de adultos de 2000.

\begin{abstract}
PROTECTION OF ADULTS IN PRIVATE INTERNATIONAL SPANISH LAW. NEWS AND CHALLENGES

Legal framework on international protection of adults in Spanish law has been recently modified through four different legal reforms: Law 7/2015 on jurisdiction rules, law 26/2015 on applicable law rules and laws 15 and 29/2015 on recognition and enforcement rules. This article analyzes these reforms through recent spanish jurisprudence and administrative decisions and underlines the convenience of the ratification of the HAPC 2000 by Spain.
\end{abstract}

Keywords: international protection of adults, jurisdiction, applicable law, recognition and enforcement, Hague Convention on international protection of adults 2000.

\footnotetext{
${ }^{86}$ BOE, de 2 de diciembre de 2010.

87 Resolución núm. 4712/2018, de 23 de marzo (RJ 2018/1886).
} 